\title{
Patient Satisfaction with Three Dental Speciality Services: A Centre-Based Study
}

\author{
Buthaina A. Al-Mudafa Mohamed A.A. Moussab Maha A. Al-Terkya \\ Ghaneema D. Al-Dakhila Alaa E. El-Farargya Sadad S. Al-Ouzairia \\ Departments of a Quality Assurance, Ministry of Health, Kuwait, and ${ }^{\mathrm{b}}$ Community Medicine and \\ Behavioural Sciences, Faculty of Medicine, Kuwait University, Kuwait
}

\section{Key Words}

Dental services · Patient satisfaction - Infection control • Quality of dental care

\begin{abstract}
Objective: To assess the level of patient satisfaction with three dental speciality services: oral surgery, periodontics, and fixed prosthodontics. Subjects and Methods: A sample of 1,242 patients, aged 16 years and over who received dental care at least twice at the main dental centre, Al-Amiri, Kuwait, were interviewed during MayAugust 1998 by independent researchers concerning their experience of previous visits. Patients reported their level of satisfaction on a 5-point Likert scale for the items in the questionnaire, which focused on four areas: access, dentist's communication, staff helpfulness, and structural aspects of the practice. Results: On average $49.4 \%(25.9-89.6 \%)$ of participating patients rated the level of care received as excellent. Areas rated poorest included waiting time for an appointment and waiting time in the clinic to access the dentist. Participants were less satisfied with doctor's explanation of illness, dental treatment and confidentiality of medical records. The areas that received excellent ratings by patients included: (a) communication (listening and understanding
\end{abstract}

complaints $40.0 \%$ and courteous treatment $57.8 \%$ ), and (b) structural aspects (availability of infection control and safety measures $89.6 \%$ and packed sterilized instruments 78.9\%). Conclusion: Findings indicate that the level of patient satisfaction was reasonably high. Areas identified as needing improvement included: dentistpatient communication skills, medical records, appointment systems, and shortening of the waiting time to access the dentist.

Copyright (C2003S. Karger AG, Basel

\section{Introduction}

Consumer opinion is an essential component of any quality improvement programme. It is an important quality indicator in measuring the outcome of any medical service and thus assists health care providers in designing health management plans $[1,2]$. Patient satisfaction is regarded as an outcome of care and is one of the major factors that contribute towards better patient compliance and consequently to better clinical outcomes [3].

Patient satisfaction with dental care is a multidimensional concept reflecting patients' expectations, values and experiences [4]. The interpretation of patient satisfaction as an overall score is, therefore, difficult. Instead,

\section{KARGER \\ Fax +41613061234 \\ E-Mail karger@karger.ch \\ www.karger.com

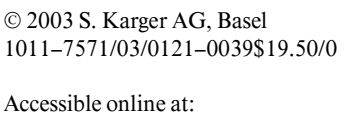

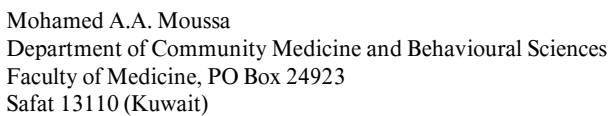


Table 1. Percentages of participants answering the items of the patient satisfaction questionnaire and mean score

\begin{tabular}{|c|c|c|c|c|c|c|c|c|}
\hline Iter & & Excellent & Good & Average & Poor & $\begin{array}{l}\text { Very } \\
\text { poor }\end{array}$ & $\begin{array}{l}\text { No } \\
\text { answer }\end{array}$ & $\begin{array}{l}\text { Mean } \\
\text { score }\end{array}$ \\
\hline \multicolumn{9}{|c|}{ Access } \\
\hline & Waiting time for an appointment & 7.8 & 27.8 & 14.0 & 16.5 & 33.2 & 0.7 & 2.60 \\
\hline & Waiting time in the clinic to access the dentist & 8.7 & 22.0 & 24.3 & 23.8 & 20.8 & 0.4 & 2.74 \\
\hline \multicolumn{9}{|c|}{ Dentists' communication } \\
\hline 3 & $\begin{array}{l}\text { The doctor treats you courteously, showing } \\
\text { thoroughness and interest in your personal situation }\end{array}$ & 57.5 & 31.2 & 5.0 & 3.9 & 2.0 & 0.4 & 4.39 \\
\hline 4 & $\begin{array}{l}\text { The doctor explains your illness and the purpose } \\
\text { of tests and treatments }\end{array}$ & 25.9 & 40.3 & 9.2 & 7.2 & 17.1 & 0.3 & 3.51 \\
\hline 5 & $\begin{array}{l}\text { The doctor listens to you and understands your } \\
\text { explanations }\end{array}$ & 40.0 & 35.3 & 4.8 & 3.3 & 14.3 & 2.3 & 3.85 \\
\hline \multicolumn{9}{|c|}{ Staff helpfulness } \\
\hline 6 & The helpfulness of the nursing staff & 39.5 & 37.5 & 7.8 & 7.3 & 5.6 & 2.3 & 4.00 \\
\hline 7 & $\begin{array}{l}\text { The helpfulness of the medical records staff and } \\
\text { keeping your records and data confidential }\end{array}$ & 27.5 & 41.2 & 13.0 & 9.4 & 8.2 & 0.7 & 3.69 \\
\hline 8 & The helpfulness of the radiology staff & 36.2 & 52.0 & 5.3 & 2.9 & 1.7 & 1.9 & 4.14 \\
\hline \multicolumn{9}{|c|}{ Structural aspects of the practice } \\
\hline 9 & $\begin{array}{l}\text { Availability of infection control and safety } \\
\text { precautions (wearing gloves, coat, mask) }\end{array}$ & 89.6 & 5.4 & 0.5 & 3.0 & 0.5 & 1.0 & 4.78 \\
\hline 10 & $\begin{array}{l}\text { Availability of packed sterilized instruments and } \\
\text { disposable consumables (cups, aprons) }\end{array}$ & 78.9 & 5.9 & 2.0 & 5.3 & 0.9 & 7.0 & 4.60 \\
\hline \multicolumn{2}{|c|}{ Overall } & 41.2 & 29.9 & 8.6 & 8.3 & 10.4 & 1.6 & 3.83 \\
\hline \multicolumn{2}{|c|}{ Excluding items 1 and 2} & 49.4 & 31.1 & 6.0 & 5.3 & 6.3 & 2.0 & 4.12 \\
\hline
\end{tabular}

comparison over defined dimensions of dental care may be more appropriate. Patient satisfaction surveys in dental practice have increased $[5,6]$. The factors studied as predictors of satisfaction in dental practice included: sociodemographic characteristics, doctor-patient relationships, communication skills, accessibility and clinic organization $[7,8]$.

Kuwait has undergone a transition of its economy and accordingly of its health care system. A quality assurance programme was established in 1987 in Kuwait with the aim of evaluating the quality of different aspects of health care. The main dental care centre (Al-Amiri) was inaugurated in 1972 and currently provides specialized care to $52.8 \%$ of dental patients in Kuwait. It includes 8 departments: oral surgery, orthodontics, pedodontics, endodontics, fixed prosthodontics, removable prosthodontics, periodontics and casualty. There are 66 dentists running 36 different clinics daily in the facility [9]. Dental care has been provided free in Kuwait since 1951 and patients access the dental centre through referral by primary health care practitioners.
Data on patient satisfaction with dental care services in Kuwait are scarce. Therefore, we conducted this study to assess the level of patient satisfaction with three dental speciality services (oral surgery, periodontics, and fixed prosthodontics) in order to gain insight into patients' priorities and identify areas for improvement.

\section{Subjects and Methods}

We designed a questionnaire for patients' evaluations of three dental speciality services. This questionnaire covered access, dentists' communication, staff helpfulness, and structural aspects of the practice. Questions on access to dental care included items concerning the appointment system, and waiting time in the clinic prior to access to the dentist. Information elicited on clinical behaviour included opinions about dentist-patient communication, staff-patient relationships, technical aspects including infection control, safety precautions, sterilized instruments and disposable consumables. We used a 5-point Likert scale with the extremes labelled 'very poor' and 'excellent' (table 1). The items were selected from published patients' satisfaction questionnaires [10, 11]. The questionnaire also solicited information concerning the patient's gender, age, educational level, and the number of previous dental visits. The validity of

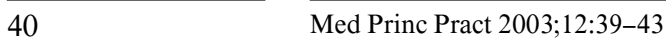


the instrument was assured through explicit translation procedures using three forward and two backward translations of the original English version into Arabic.

The study was conducted in the main dental centre (Al-Amiri) in Kuwait during May-August 1998 by independent investigators. Verbal informed consent was obtained from patients by the independent interviewers who assured them of the anonymity and confidentiality of their responses. Patients who agreed to participate were interviewed in a private area while they were waiting to access the dentist in the three dental speciality services studied, and were asked about their previous visits. The inclusion criteria selected patients 16 years old and above who had received dental care on at least two previous occasions in the centre. The sample included 1,329 patients, but 87 $(6.5 \%)$ of them refused to participate, either because of shortage of time, or their unwillingness. Questionnaires from 1,242 participants (93.5\% response rate) entered the final analysis. This sample size was estimated to provide adequate power to detect significant differences between mean patient satisfaction score according to different factors such as gender, age, education level, dental speciality service, and number of visits.

\section{Statistical Methods}

Data were processed using the SPSS statistical package, version 11.0 with $\mathrm{p} \leq 0.05$ as the cut-off level for significance. A score was assigned to each category of the 5-point Likert scale as follows: excellent 5 , good 4 , average 3 , poor 2 , very poor 1 . A satisfaction score was computed for each item by multiplying the number in each category by the respective score, and summing over all categories. The mean satisfaction score for each item was then obtained by dividing the sum of scores obtained by the total number of participants. Normality of patient satisfaction scores distributions were tested using the normal plot, and Shapiro-Francia $\mathrm{W}^{\prime}$ test [12].

Reliability of the instrument scale was measured by the reliability coefficient (Cronbach's alpha) using the SPSS reliability analysis. The coefficient determines the extent to which items of the questionnaire are related, and identifies items that should be excluded. We used the alpha model of reliability, a model of internal consistency based on the average inter-item correlation. The reliability of the instrument was high (Cronbach's alpha $=0.892$ ). To identify the dimensions that explain the pattern of correlations within the 10 questionnaire item scores, we used the factor analysis, SPSS. This analysis reveals any significant overlap between items, and defines unique uncorrelated factors. We used the principal components method for factor analysis extraction based on eigenvalues. Factor analysis did not show any subdimensions in the satisfaction scale. This allowed us to use a composite score for the satisfaction scale. Parametric tests were used to compare mean satisfaction levels of various subgroups, such as males versus females, age groups, education level, number of visits, and department. The Student's t test was used to compare two groups, and the one-way analysis of variance was used for comparison of more than two groups.

\section{Results}

The mean age of participants was 34.8 years, standard deviation (SD) 11.5 years $(36.6 \%$ below $30,55.1 \%$ between 30 and 50, and 8.3\% older than 50), and $60.6 \%$ were women. Concerning education, $4.7 \%$ of participants were illiterate and $36.7 \%$ were university graduates. Out of the participants, $39.6 \%$ were visiting the oral surgery department, $30.7 \%$ the fixed prosthodontics department and $29.7 \%$ the periodontic department.

Table 1 depicts the patients' ratings of the questionnaire items. On average, 49.4\% (25.9-89.6\%) of participants rated the dental speciality services that they had received as excellent, if we exclude the two items on access, and $80.5 \%$ as excellent or good. The two access items, waiting time for an appointment and waiting time in the clinic to access the dentist, were the lowest rated items (only $7.8 \%$ excellent vs. $33.2 \%$ very poor for waiting time for an appointment; $8.7 \%$ excellent vs. $20.8 \%$ very poor for waiting in the clinic to access the dentist). Participants reported low satisfaction with some particular aspects of dentists' communications: doctor's explanation of illness and treatment $(25.9 \%$ excellent vs. $17.1 \%$ very poor). They were also poorly satisfied with the helpfulness and organization of the medical records staff $(27.5 \%$ excellent vs. $8.2 \%$ very poor).

On the other hand, patients praised other aspects of dental speciality services related to dentists' communications: listening of dentists and understanding their explanations $(40.0 \%$ excellent vs. $14.3 \%$ very poor), doctors treating them courteously showing thoroughness and interest in their personal situations $(57.5 \%$ excellent vs. $2.0 \%$ very poor). Other positive aspects were connected with structural features of the practice: availability of infection control and safety precautions $(89.6 \%$ excellent vs. $0.5 \%$ very poor), availability of packed sterilized instruments and disposable consumables (78.9\%) excellent vs. $0.9 \%$ very poor). Of the respondents, $29.9 \%$ rated all the items specified in the questionnaire as good.

Mean score for the items of the questionnaire ranged from 3.51 to 4.78 out of 5 with the exception of the two low-rated access items, waiting time for an appointment and waiting in the clinic to access the dentist, which generated mean scores of 2.60 and 2.74 , respectively. The composite score for the satisfaction scale was 75.6 points out of 100 (SD 9.8) which increases to 81.2 (SD 3.6) if the two access items are excluded.

The mean satisfaction score showed that female patients were more satisfied with the dental services than males (males 76.1; females 77.7; $p=0.029$ ). The satisfaction score also differed according to the department of dental care. Patients were more satisfied with oral surgery than with fixed prosthodontics or periodontics departments (oral surgery, 79.0; fixed prosthodontics, 77.9; periodontics, 73.3; $\mathrm{p}<0.001)$. Patients with more frequent 
Table 2. Mean patient satisfaction score according to the studied background factors

\begin{tabular}{lccc}
\hline & Mean & SD & p value \\
\hline Gender & & & 0.029 \\
$\quad$ Male & 76.1 & 11.5 & \\
$\quad$ Female & 77.7 & 11.3 & \\
Age, years & & & 0.076 \\
$\quad<30$ & 76.7 & 11.1 & \\
$\quad 30-50$ & 76.9 & 11.4 & \\
$\quad>50$ & 79.6 & 12.3 & \\
Education & & & 0.802 \\
$\quad$ Below university & 77.2 & 11.2 & \\
$\quad$ University and above & 77.0 & 11.7 & \\
Department & & & $<0.001$ \\
$\quad$ Oral surgery & 79.0 & 9.1 & \\
$\quad$ Fixed prosthodontics & 77.9 & 9.5 & \\
$\quad$ Periodontics & 73.3 & 15.0 & \\
Number of visits & & & 0.006 \\
$\quad<5$ & 77.5 & 11.1 & \\
$\quad \geq 5$ & 74.8 & 12.3 & \\
\hline
\end{tabular}

visits were less satisfied with dental care ( $<5$ visits, 77.5 ; $\geq 5$ visits, $74.8 ; \mathrm{p}=0.006$ ). However, the mean satisfaction score did not differ according to age or education level (table 2).

\section{Discussion}

The level of satisfaction with dental care in the main dental centre in Kuwait was shown to be relatively high. In all but two aspects, a high percentage of participants expressed satisfaction with the selected items. The two items with lowest satisfaction scores related to access to dental care: waiting time for an appointment and waiting in the clinic to access the dentist. This result contrasts with a Finnish study [13], in which patients were satisfied with accessibility to dental care. Dissatisfaction with waiting time in the clinic reveals an important problem that needs to be resolved, possibly through limiting the number of patients to reduce the waiting time. Organizational changes to allow dentists sufficient time with their patients could also shorten clinic waiting times. Doctor's explanation of illnesses and treatments to patients also received a low evaluation. These findings invite improvement in dental professional training programmes and continuing medical education activities to promote dentist-patient communication skills.

Highly rated items connected with the dentist's clinical behaviour in Kuwait included: the capacity of doctors to listen to patients, their understanding of patient's explanations, treating patients courteously, showing thoroughness and interest in patients' personal situations. Other highly rated items were related to the organization of dental care: availability of infection control and safety measures, packed sterilized instruments and disposable consumables. We believe that the reasons for this high level of satisfaction are the compliance of doctors with the infection control guidelines for dental practice in Kuwait and the long-established infection control programme. This result is in agreement with other studies [14, 15].

Female, well-educated patients of middle age were predominant in the present study since dental services are widely utilized by this category of patients to maintain a high level of dental care and hygiene. Female patients were more satisfied with dental care than male patients. This result is in accordance with two other studies [16, 17] which reported that women are usually more satisfied with dental care than men. The authors attributed their finding to women's greater exposure to dental services which would be likely to moderate their expectations. This view contradicts the result of our present study in which patients recording more frequent visits reported less satisfaction with dental care. The satisfaction score did not differ with the age of the patient. This result is consistent with another study [18] which did not show a significant relationship between age and satisfaction with dental care.

Similarly, the satisfaction score did not differ with the education of the patients. It is noteworthy that although a study [16] concluded that more highly educated patients reported more satisfaction with their dental care, another investigation [19] reported that dental patients with no formal education or with less education were more satisfied. Moreover, the satisfaction score differed according to the dental speciality service, a finding consistent with another study [13].

Naturally, this study is subject to the limitations of patient satisfaction research. Conducting the survey in the facility prior to the dental visit probably poses methodological issues as a recall of past visits to the clinic could be affected by the experience of the current visit. It is possible that patients who were waiting are more likely to be satisfied than those who have just received care and that conducting the survey prior to receipt of treatment may contaminate the respondent's thinking. In order to alleviate the potential bias that might emerge as a result of these issues, patients were interviewed about their previous visits, not the current visit. 


\section{Conclusion}

The level of patient satisfaction with the three dental speciality services targeted in this study is reasonably high. However, this study revealed areas where improvement is needed. Dentist-patient communication skills should be part of the core curricula for undergraduate and postgraduate dental education and for effective communication to take place, dentists need more time for consultation with patients. This research also highlights the need for better management practices including an efficient system for appointments.

\section{References}

1 Rowlands HS, Rowland BL: Hospital and Health Systems Quality Management, ed 1. Gaithersburg, Aspen, 1996, vol 2.

2 Ball R: Practical marketing for dentistry. 3. Relationship marketing and patient/customer satisfaction. Br Dent J 1996;180:467-472.

3 Donabedian A: The Lichfield Lecture. Quality assurance in health care: Consumers' role. Qual Health Care 1992;1:247-251.

4 Sitzia J, Wood N: Patient satisfaction: A review of issues and concepts. Soc Sci Med 1997;45: 1829-1843.

5 Kress G, Shulman JD: Consumer satisfaction with dental care: Where have we been, where are we going? J Am Coll Dent 1997;64:9-15.

6 Kalkwarf KL: Patient-centred care and today's dental practice. J Am Coll Dent 1997;64:6-8.

7 Hall JA, Dornan MC: Patient sociodemographic characteristics as predictors of satisfaction with medical care: A meta-analysis. Soc Sci Med 1990;30:811-818.
8 Cohen G: Age health status in a patient satisfaction survey. Soc Sci Med 1996;42:10851093.

9 Bilal MS: Annual Report of Dental Department. Kuwait, Ministry of Health, 1997.

10 Hakeberg M, Heidari E, Norinder M, Berggren U: A Swedish version of the Dental Visit Satisfaction Scale. Acta Odontol Scand 2000;58:1924.

11 Chapko MK, Bergner M, Green K, Beach B, Milgrom P, Skalabrin N: Development and validation of a measure of dental patient satisfaction. Med Care 1985;23:39-49.

12 Shapiro SS, Francia RS: An approximate analysis of variance test for normality. J Am Statist Ass 1972;67:215-216.

13 Tuominen R, Tuominen M: Satisfaction with dental care among elderly Finnish men. Community Dent Oral Epidemiol 1998;26:95-100.
14 Hoff DA, Sampieri PA, Rickert V, Goldstein J: Consumers' awareness of barrier protection in dentistry. J Dent Hyg 1990;64:446-448.

15 McCarthy GM, Koval JJ, MacDonald JK: Occupational injuries and exposures among $\mathrm{Ca}$ nadian dentists: The results of a national survey. Infect Control Hosp Epidemiol 1999;20: 331-336.

16 Reifel NM, Rana H, Marcus M: Consumer satisfaction. Adv Dent Res 1997;11:281-290.

17 Gopalakrishna P, Munnaleneni V: Influencing satisfaction for dental services. J Health Care Mark 1993;13:16-22.

18 DiMatteo MR, Hays R: The significance of patients' perceptions of physician conduct: A study of patient satisfaction in a family practice center. J Community Health 1980;6:18-34.

19 Handelman SL, Fan-Hsu J, Proskin HM: Patient satisfaction in four types of dental practice. J Am Dent Assoc 1990;121:622-630. 